\title{
Genetic divergence among Wheat breeding lines for production traits
}

\author{
Faiza Zoha Zafar ${ }^{1}$, Fida Mohammad ${ }^{1}$, Fahim Ullah Khan ${ }^{1,2 *}$ Gul Ghuttai ${ }^{1}$ \\ and Wasif Ullah Khan ${ }^{1}$ \\ ${ }^{1}$ Department of Plant Breeding \& Genetics, The University of Agriculture Peshawar \\ ${ }^{2}$ Barani Agricultural Research Station, Kohat-Pakistan \\ *Corresponding author's email: fahimbiotech@gmail.com \\ Citation \\ Faiza Zoha Zafar, Fida Mohammad, Fahim Ullah Khan, Gul Ghuttai \& Wasif Ullah Khan. Genetic divergence \\ among wheat breeding lines for production traits. Pure and Applied Biology. Vol. 4, Issue 3, 2015, pp 427-433. \\ http://dx.doi.org/10.19045/bspab.2015.43019
}

Received: 15/04/2015 $\quad$ Revised: 03/07/2015

Accepted: 10/07/2015

\begin{abstract}
Development of superior genotypes is one of the prime objective of all plant breeding programmes. To investigate genetic divergence and traits association among yield and yield associated traits, an experiment was conducted at New Developmental Research Farm, The University of Agriculture, Peshawar during 2013-2014. Twenty wheat genotypes was planted in randomized complete block (RCB) design with three replications under rainfed condition. Data was recorded on days to heading, days to maturity, plant height, tillers $\mathrm{m}^{-2}$, grains spike ${ }^{-1}$, 1000-grain weight, and grain yield. Significant differences were observed among wheat genotypes for days to heading, maturity and plant height, whereas non-significant differences were observed for rest of the traits. Maximum values for days to heading ( 94 days), days to maturity (167 days), plant height $(96.3 \mathrm{~cm})$ were recorded for genotypes KT-338. Maximum values for tillers $\mathrm{m}^{-2}$ (187) was recorded for genotype NRL-1009, grains spike $^{-1}$ (54) for genotype PS-21, 1000-grain weight (59.3 g) for genotype NRL-1130, and grain yield (3500 kg $\mathrm{ha}^{-1}$ ) for genotype PS-20. The grain yield had significant positive correlation with days to maturity, tillers $\mathrm{m}^{-2}$, and 1000-grain weight, showing that these traits could be considered in devising selection criteria for improvement in grain yield. PS-20 and NRL-1130 out yielded the check cultivars and can be recommended for further use in different breeding program.
\end{abstract}

Keywords: Wheat; Drought; Genetic variability; Correlation; Advance lines.

\section{Introduction}

Wheat (Triticum aestivum L.) has been a staple food of major civilizations since 8000 years. It is the world's most important cereal and leading grain crop of the temperate climates of the world. Although cultivated under a wide range of climatic conditions, the most extensive production of wheat is in areas where the winters are cool and the summers are comparatively hot [1].
Genetic diversity serves as a way for populations to adapt to changing environments. With more variation, it is more likely that some individuals in a population will possess variations of alleles that are suited for the environment. Genetic diversity also reduces the incidence of unfavorable inherited traits. In a small, isolated population of organisms, individuals may be forced to breed with close relatives. When 
this happens, the genetic makeup of the individuals becomes more and more uniform, and genetic flaws become increasingly more common. This phenomenon is called inbreeding [2].

Correlation studies provide a better understanding of the association of different characters with grain yield. The existing relationships between traits are, generally, determined by the genotypic, phenotypic and environmental correlations. The phenotypic correlation measures the degree of association of two variables and is determined by genetic and environmental factors. The latter is mainly responsible for the correlation of traits of low heritability, such as grain yield, for instance. The genotypic correlation on the other hand, which represents the genetic portion of the phenotypic correlation, is the only one of inheritable nature and therefore used to orient breeding programs [3]. Keeping in view the importance of wheat, an experiment was designed to find out the extent of genetic diversity among wheat breeding lines, correlations among yield and yield associated traits and to identify high yielding wheat genotype for future evaluation.

\section{MATERIALS AND METHODS}

The present experiment was conducted at New Developmental Research Farm, The University of Agriculture, Peshawar during 2013-2014 crop season. Experimental material comprised of twenty elite bread wheat genotypes including two check cultivars viz. Shahkar-13 and Janbaz. The experimental material was received from Directorate of Outreach, Khyber Pakhtunkhwa Agriculture Research System as $2^{\text {nd }}$ Khyber Pakhtunkhwa Wheat Yield Trial Rainfed ( $2^{\text {nd }}$ KPWYT). The experimental material was planted in randomized complete block (RCB) design, with 3 replications. Each entry consisted of six rows with row length of 5 meter and row to row distance of $30 \mathrm{~cm}$. Standard agronomic practices were carried out throughout the growing season. Observations were recorded on ten plants randomly selected in each genotype in each replication. Data was recorded on days to heading, days to maturity, flag leaf area $\left(\mathrm{cm}^{2}\right)$, plant height (cm), spike length $(\mathrm{cm})$, tillers $\mathrm{m}^{-2}$, grains spike $^{-1}, 1000$ grain weight $(\mathrm{g})$, and grain yield $\left(\mathrm{kg} \mathrm{ha}^{-1}\right)$.

Table 1. List of genotypes studied during the studies.

\begin{tabular}{|l|l|l|l|l|l|}
\hline S. No & Genotype & Breeding Centre & S.No & Genotypes & Breeding Centre \\
\hline 1 & NRL-1123 & NIFA-Peshawar & 11 & PS-18 & CCRI-Pirsabak \\
\hline 2 & NRL-1009 & NIFA-Peshawar & 12 & PS-19 & (CCRI-Pirsabak) \\
\hline 3 & NRL-1130 & NIFA-Peshawar & 13 & PS-20 & (CCRI-Pirsabak) \\
\hline 4 & NRL-1139 & NIFA-Peshawar & 14 & PS-21 & (CCRI-Pirsabak) \\
\hline 5 & NRL-1241 & NIFA-Peshawar & 15 & AUP-0484 & (PBG,UOA Peshawar) \\
\hline 6 & AUP-3186 & PBG,UOA Peshawar & 16 & AUP-2670 & (PBG,UOA Peshawar) \\
\hline 7 & KT-338 & BARS, Kohat & 17 & BAFFA-3 & (ARS, Baffa) \\
\hline 8 & DN-102 & ARI, D.I Khan & 18 & BAFFA-4 & (ARS, Baffa) \\
\hline 9 & DN-104 & ARI, D.I Khan & 19 & Shahkar-13 & (General check) \\
\hline 10 & PS-17 & CCRI-Pirsabak & 20 & Janbaz & (Local check) \\
\hline
\end{tabular}




\section{Statistical analysis \\ Analysis of Variance}

The data recorded on each parameter were subjected to analysis of variance (ANOVA) techniques appropriate for a randomized complete block design through Statistix ver. 8.1 computer programme. The mean differences among wheat genotypes for different yield and yield related traits was determined by using Least Significant Differences (LSD) test at 5\% level of probability.

\section{Correlation analysis}

Pearson correlation coefficient among yield and associated traits were computed using computer software IBM-SPSS ver. 16.1 following the procedure of [15].

\section{Results and discussion} Days to heading

Analysis of variance revealed highly significant difference among genotypes for days to heading (Table 2). Significant differences among wheat genotypes for days to heading were also reported [17]. Days to heading ranged from 77 to 94 with the mean value of 88 days (Table 3 ). Minimum days to heading were recorded for genotype AUP-0484 (77 days), followed by genotype NRL-1009 (80 days), and AUP-3186 (81 days). On the other hand, maximum days to heading were observed for genotype KT-338 (94 days), followed by genotypes NRL-1123, NRL1241, and PS-20 (each with 92 days).

Days to heading showed highly significant positive correlation with days to maturity $\left(\mathrm{r}=0.89^{* *}\right)$ and plant height $\left(\mathrm{r}=0.56^{* *}\right)$, whereas non-significant association was observed with the rest of the traits (Table 4). Similar results were also reported by [3].

\section{Days to maturity}

Mean squares for days to maturity showed highly significant differences among 20 wheat genotypes (Table 2). Days to maturity varied from 157 to 167 with the mean value of 162 days (Table 3). The results are in accordance with the earlier findings, who also observed significant differences among wheat genotypes for days to maturity $[4,17]$. Minimum days to maturity were recorded for genotype AUP0484 (157 days), followed by NRL-1009 (159 days), and AUP-3186 and Janbaz (160 days). And maximum days to maturity was recorded for KT-338 (167) days, followed by PS-19 (165 days) and NRL-1139 and NRL-1241 (each 164 days).

Days to maturity showed significant positive phenotypic correlation with plant height $\left(\mathrm{r}=0.43^{*}\right)$ and grain yield $\left(\mathrm{r}=0.40^{*}\right)$, whereas non-significant association was observed with rest of the traits (Table 4). Similarly [5] reported significant positive correlation with days to $50 \%$ heading but reported non-significant phonotypic correlation with rest of the traits.

\section{Plant height (cm)}

The genotypic mean squares depicted that differences among 20 wheat genotypes for plant height were significant (Table 2). Plant height was in range of 79.3 - 96.3 with the mean value of 86.30 (Table 3 ). The results are in accordance with [6-9]. Minimum plant height was recorded for genotype NRL-1009, AUP-3186, and Shahkar-13 $(79.3 \mathrm{~cm}$ each) followed by genotype AUP-0484 $(81.3 \mathrm{~cm})$ and DN-102 (81.6), while maximum plant height was observed for KT-338 (96.3), followed by genotype NRL-1123, DN-104 (each with 93.6am) and NRL-1241 (92.3).

Plant height had negatively non-significant correlation $(\mathrm{r}=-0.16)$ with tillers $\mathrm{m}^{-2}$ and positively non-significant correlation with rest of the traits (Table 4).

\section{Tillers $\mathbf{~ m}^{-2}$}

Twenty (20) wheat genotypes showed nonsignificant differences for tillers $\mathrm{m}^{-2}$ (Table 2). Tillers $\mathrm{m}^{-2}$ varied from $117-187$ with the mean value of 151.9 (Table 3). Significant differences among wheat genotypes for the number of productive tillers $\mathrm{m}^{-2}$ and grain 
yield [10]. The Minimum number of tillers $\mathrm{m}^{-2}$ were observed for PS-21 (117) followed by BAFFA-4 (121) and maximum number of tillers $\mathrm{m}^{-2}$ were observed for NRL-1009 (187) followed by NRL-1130 (182).

Tillers $\mathrm{m}^{-2}$ showed highly significant negative correlation with grains spike ${ }^{-1}(r=-$ $0.79 * *)$ and significant positive correlation with 1000 -grain weight $\left(\mathrm{r}=0.47^{*}\right)$ and grain yield $(0.53 *)$ (Table 4). Similarly, [10] obtained significantly negative correlation of productive tillers $\mathrm{m}^{-2}$ with grains spike 1

\section{Grains spike ${ }^{-1}$}

Analysis of variance revealed nonsignificant differences among 20 wheat genotypes for grains spike ${ }^{-1}$ (Table 2). Grains spike ${ }^{-1}$ varied from 32-54, with the mean value of 43.05 (Table 3). Similar results were obtained by $[10,16,17]$ who observed significant differences for grains spike $^{-1}$. Minimum grains spike ${ }^{-1}$ were obtained by NRL-1139 (32) followed by NRL-1130 (35), and NRL-1241, AUP3186 (39 each). And maximum grains spike $^{-1}$ was obtained by PS-21 (54), followed by BAFFA-3 (53), and BAFFA4 (52).

Grains spike ${ }^{-1}$ had highly significant negative correlation with 1000 grain weight $(\mathrm{r}=-0.64 * *)$ and negatively nonsignificant correlation with grain yield $(\mathrm{r}=$ 0.20) (Table 4). Earlier, [2] revealed highly significant positive correlation was obtained by grain yield plant ${ }^{-1}$ with number of tillers plant ${ }^{-1}$ and number of grains spike $^{-1}$.

\section{0 grain weight $(\mathrm{g})$}

Mean squares for 1000 grain weight showed non-significant differences among 20 wheat genotypes (Table 2). The 1000 grain weight was in range of 38.6-59.3, with the mean of 46.28 (Table 3 ). The results do not agree with [11, 16-17], who got significant results for 1000-grain weight among the genotypes. The minimum 1000 grain weight was obtained by genotype NRL-1123 (38.6) followed by BAFFA-4 (39.6) and BAFFA-3 (40.0). On the other hand, maximum 1000 grain weight was obtained by NRL-1130 (59.3) followed by DN-104 (53.6) and PS-19 (53.3).

1000 grain weight depicted significant positive correlation with grain yield $(\mathrm{r}=$ $0.56^{*}$ ) (Table 4). The results do not agree with [12], who obtained non-significant positive phenotypic correlation with grain yield plant ${ }^{-1}$.

\section{Grain yield $\left(\mathrm{kg} \mathrm{ha}^{-1}\right)$}

Mean squares for grain yield showed nonsignificant differences among 20 wheat genotypes (Table 2). The grain yield varied from 2389.0-3500.0, with the mean of 2834.93 (Table 3). The results agree with $[9,13,16,17]$ also reported non-significant differences for grain yield in different genotypes. The results do not concide with the work of $[14,16]$, as they revealed highly significant differences among the genotypes for grain yield. The minimum grain yield was revealed by the genotype AUP-2670 (2389.0), followed by genotype Janbaz (2454.9) and BAFFA-4 (2489.0), while maximum grain yield was obtained by genotype PS-20 (3500.0) followed by genotype NRL-1130 (3305.3) and NRL1123 (3172.0).

Phenotypic correlation of grain yield with days to maturity $\left(\mathrm{r}=0.40^{*}\right)$, Tillers $\mathrm{m}^{-2}$ $\left(\mathrm{r}=0.53^{*}\right)$, and 1000 -grain weight $\left(\mathrm{r}=0.56^{*}\right)$ were observed to be significant and positive. Phenotypic correlation of grain yield with other traits was non-significant, but negatively non-significant with grains spike $^{-1}$ (Table 4), whereas, [4] concluded that grain yield had significant correlations with spikes plot $^{-1}$, grains spike ${ }^{-1}$, grain weight spike $^{-1}, 1000$ grain weight, and harvest index. 
Table 2. Mean squares for various yield traits of 20 wheat genotypes evaluated at The University of Agriculture, Peshawar during 2013-14.

\begin{tabular}{lcccc}
\hline Traits & $\begin{array}{c}\text { Replication } \\
(\mathbf{d f = 2})\end{array}$ & Genotypes $(\mathbf{d f = 1 9 )}$ & Error $(\mathbf{d f = 4 6 )}$ & $\begin{array}{c}\text { CV } \\
(\boldsymbol{\%})\end{array}$ \\
\hline Days to heading & 22.74 & $62.64^{* *}$ & 2.36 & 1.75 \\
Days to maturity & 23.41 & $16.83^{* *}$ & 2.41 & 0.96 \\
Plant height $(\mathrm{cm})$ & 299.16 & $82.30^{*}$ & 20.95 & 5.30 \\
Tillers m$^{-2}$ & 457.03 & $1432.89^{\mathrm{NS}}$ & 841.81 & 19.06 \\
Grain spike $^{-1}$ & 206.23 & $115.66^{\mathrm{NS}}$ & 90.02 & 22.02 \\
1000 grain weight $(\mathrm{g})^{\mathrm{NS}}$ & 138.11 & $103.56^{\mathrm{NS}}$ & 174.46 & 28.52 \\
${\text { Grain yield }\left(\mathrm{kg} \mathrm{ha}^{-1}\right)}^{560777}$ & $258316^{\mathrm{NS}}$ & 167196 & 14.42 \\
\hline
\end{tabular}

Table 3. Mean performance for various yield traits of 20 wheat genotypes evaluated at The University of Agriculture, Peshawar during 2013-14.

\begin{tabular}{llllllll}
\hline Genotypes & $\begin{array}{l}\text { Days to } \\
\mathbf{5 0 \%} \text { heading }\end{array}$ & $\begin{array}{l}\text { Days to } \\
\text { maturity }\end{array}$ & $\begin{array}{l}\text { Plant } \\
\text { height }\end{array}$ & $\begin{array}{l}\text { Tillers } \\
\text { m }^{-2}\end{array}$ & $\begin{array}{l}\text { Grains } \\
\text { spike }^{-1}\end{array}$ & $\begin{array}{l}\text { 1000 grain } \\
\text { weight }\end{array}$ & $\begin{array}{l}\text { Grain } \\
\text { yield }\end{array}$ \\
\hline NRL-1123 & 92 & 163 & 93.6 & 164 & 51 & 38.6 & 3172.0 \\
NRL-1009 & 80 & 159 & 79.3 & 187 & 36 & 45.6 & 2983.3 \\
NRL-1130 & 90 & 163 & 88.6 & 182 & 35 & 59.3 & 3305.3 \\
NRL-1139 & 90 & 164 & 83.4 & 198 & 32 & 51.9 & 2788.7 \\
NRL-1241 & 92 & 164 & 92.3 & 153 & 39 & 45.0 & 2600.0 \\
AUP-3186 & 81 & 160 & 79.3 & 160 & 39 & 51.6 & 2916.7 \\
KT-338 & 94 & 167 & 96.3 & 143 & 49 & 46.0 & 3116.7 \\
DN-102 & 90 & 164 & 81.6 & 175 & 40 & 42.0 & 2966.3 \\
DN-104 & 90 & 163 & 93.6 & 149 & 38 & 53.6 & 2766.7 \\
PS-17 & 89 & 161 & 85.6 & 128 & 46 & 43.3 & 2539.0 \\
PS-18 & 83 & 160 & 86.0 & 154 & 40 & 47.0 & 2766.7 \\
PS-19 & 90 & 165 & 85.3 & 148 & 42 & 53.3 & 3066.7 \\
PS-20 & 92 & 163 & 91.0 & 158 & 43 & 54.6 & 3500.0 \\
PS-21 & 87 & 161 & 82.0 & 117 & 54 & 44.0 & 2728.0 \\
AUP-0484 & 77 & 157 & 81.3 & 155 & 42 & 41.0 & 2661.0 \\
AUP-2670 & 84 & 160 & 90.3 & 128 & 45 & 41.3 & 2389.0 \\
BAFFA-3 & 90 & 164 & 85.3 & 133 & 53 & 40.0 & 2811.0 \\
BAFFA-4 & 91 & 162 & 83.6 & 121 & 52 & 39.6 & 2489.0 \\
Shahkar-13 & 90 & 164 & 79.3 & 153 & 39 & 46.6 & 2677.7 \\
Janbaz & 87 & 160 & 88.4 & 132 & 46 & 41.38 & 2454.9 \\
\hline MEAN & 88 & 162.2 & 86.305 & 151.9 & 43.05 & 46.28 & 2834.93 \\
\hline LSD(0.05) & 2.024 & 2.024 & 2.024 & 2.024 & 2.024 & 2.024 & 2.024 \\
\hline
\end{tabular}


Table 4. Correlation coefficient among various yield traits of 20 wheat genotypes evaluated at The University of Agriculture, Peshawar during 2013-14.

\begin{tabular}{lccccccc}
\hline \multicolumn{1}{c}{ Traits } & $\begin{array}{c}\text { Days to } \\
\text { heading }\end{array}$ & $\begin{array}{c}\text { Days to } \\
\text { maturity }\end{array}$ & $\begin{array}{c}\text { Plant } \\
\text { height }\end{array}$ & $\begin{array}{c}\text { Tillers } \\
\mathrm{m}^{-2}\end{array}$ & $\begin{array}{c}\text { Grains } \\
\text { spike }^{-1}\end{array}$ & $\begin{array}{c}1000 \\
\text { grain } \\
\text { weight }\end{array}$ & $\begin{array}{c}\text { Grain } \\
\text { yield }\end{array}$ \\
\hline $\begin{array}{l}\text { Days to } \\
\text { heading }\end{array}$ & 1 & $0.88^{* *}$ & $0.56^{* *}$ & -0.09 & 0.23 & 0.13 & 0.28 \\
\hline $\begin{array}{l}\text { Days to } \\
\text { maturity }\end{array}$ & 1 & $0.43^{*}$ & 0.09 & 0.05 & 0.26 & $0.40^{*}$ \\
\hline $\begin{array}{l}\text { Plant } \\
\text { height(cm) }\end{array}$ & & 1 & -0.16 & 0.20 & 0.09 & 0.22 \\
\hline $\begin{array}{l}\text { Tillers m }{ }^{-2} \\
\text { Grain spike }\end{array}$ & & & 1 & $-0.79 * *$ & $0.47^{*}$ & $0.53^{*}$ \\
\hline $\begin{array}{l}1000 \text { grain } \\
\text { weight }(\mathrm{g})\end{array}$ & & & 1 & $-0.64^{* *}$ & -0.20 \\
\hline
\end{tabular}

$*$ and ${ }^{*}=$ Significant and highly Significant at $5 \%$ and $1 \%$ probability, respectively.

\section{Conclusion}

Significant differences were observed among wheat genotypes for days to heading, maturity and plant height, whereas nonsignificant differences were observed for rest of the traits. The grain yield had significant positive correlation with days to maturity, tillers $\mathrm{m}^{-2}$ and 1000-grain weight, showing that these traits could be considered in devising selection criteria for improvement in grain yield. PS-20 and NRL-1130 out yielded the check cultivars and can be recommended for further use in different breeding programmes.

\section{References}

1. Peterson, RF (1965) Wheats, Botany, Cultivation, and Utilization. Leonard Hill Books, London

2. Kalimullah, Khan SJ, Irfaq M \& Rehman HU (2012). Gentetic variability, correlation and diversity studies in bread wheat (Triticum aestivum L.) germplasm. The Journal of Animal \& Plant Sciences 22(2): 330-333.

3. Mohammad T, Haider S, Amin M, Khan MI \& Zamir R (2005). Path coefficient and correlation studies of yield and yield associated traits in candidate bread wheat (Triticum aestivum L.) lines. Suranaree $J$ Science Technol 13(2):175-180.

4. Khan A, Mohammad F, Hassan G \& Khalil IH (2012). Genotypic competition among elite wheat breeding lines under irrigated and rainfed conditions. Sarhad J Agric 28(1): 4752.

5. Mohammad F, Shah SMA, Swati MS, Shehzad T \& Iqbal S (2004). Genotypic variability for yield and morphological traits in bread wheat. Sarhad J Agric 20(1): 67-70.

6. Zubair M, Chaudhry AR, Khan IA \& Bakhsh (1987). Combining ability studies in bread wheat (Triticum aestivum L.). Pak J Bot 19(1): 75-80.

7. Chaudhry MH, Subhani GM, Khan FA, Ali MA, Khan NI \& Sattar A (1994). Combining ability analysis for physiological and agronomic traits of wheat. J Agric Res 32(3): 227-237.

8. Taleebi, AR \& Beigi AH (1996). Study of combining ability and heterosis in 
bread wheat diallel crosses. Iranian $J$ Agric Sci 27(2): 67-75.

9. Said A, Ahmad I \& Hussain T (2007). Performance of different wheat genotypes under environmental conditions of Peshawar Valley. Sarhad J Agric 23(3): 545-548.

10. Shah Z, Shah SMA, Hassnain A, Ali S, Khalil IH \& Munir I (2007). Genotypic variation for yield and yield related traits and their correlation studies in wheat. Sarhad $\mathbf{J}$ Agric 23(3): 633-636.

11. Firouzian, A (2003). Heritability and genetic advance of grain yield and its related traits in wheat. Pak J Biol Sci 24(6): 2020-2023.

12. Anwar J, Ali MA, Hussain M, Sabir W, Khan MA, Zulkiffal M \& Abdullah M (2009). Assessment of yield criteria in bread wheat through correlation and path analysis. The J of Animal \& Plant Sci 19(4): 185-188.

13. Maloo, SR (1987). Combining ability for grain yield and its contributing characters in durum wheat. Indian $J$ Agric Sci 57(8): 535-538.

14. Afridi N \& Khalil IH (2007). Genetic improvement in yield related traits of wheat under irrigated and rainfed environments. Sarhad J Agric 23(4):965-972.

15. Khan FU, Raziuddin \& Khalil IA (2013). Correlation and factorwise contribution of various traits related to yield in rapeseed (Brassica napus L.). American-Eurasian J Agric \& Environ Sci 13 (1): 101-104.

16. Jan S, Mohammad F \& Khan FU (2015). Genetic potential and heritability estimates of yield traits F3 segregating populations of bread wheat. Int'l J Environ 4(2): 106-115.

17. Khan I, Mohammad F \& Khan FU (2015). Estimation of genetic parameters of yield and yield related traits in wheat genotypes under rainfed conditions. Int'l $J$ Environ 4(2): 193-205. 